\title{
Suprastructure Maxillary Swing for JNA: A Novel Approach to avoid Complication
}

\author{
${ }^{1}$ Chirom A Singh, ${ }^{2}$ Ashutosh Hota, ${ }^{3}$ Madan P Gupta, ${ }^{4}$ Vishav Yadav, ${ }^{5}$ Bhinyaram Jat
}

\begin{abstract}
Juvenile nasopharyngeal angiofibroma (JNA) is a highly vascular tumor in which surgical excision is the main treatment modality. Wide exposure of the surgical field helps in complete surgical excision by subperiosteal dissection with a good vascular control. Conventional maxillary swing is a suitable approach for tumor with lateral extension. Palatal fistula is the major drawback of this approach. To avoid this complication, suprastructure maxillary swing is a suitable approach in which only the suprastructure of the maxilla needs to be swung instead of whole of the maxilla. The palatal cuts and lip split can be avoided with very little compromise in exposure.
\end{abstract}

Keywords: Juvenile nasopharyngeal angiofibroma, Maxillary swing, Nasopharyngeal angiofibroma.

How to cite this article: Singh CA, Hota A, Gupta MP, Yadav V, Jat B. Suprastructure Maxillary Swing for JNA: A Novel Approach to avoid Complication. Int $\mathrm{J}$ Otorhinolaryngol Clin 2016;8(1):26-28.

\section{Source of support: Nil \\ Conflict of interest: None}

\section{INTRODUCTION}

Juvenile nasopharyngeal angiofibroma (JNA) is a benign locally aggressive tumor with a propensity to involve base of pterygoid and skull base foramina. Although endoscopic internal approach is the preferable method for this benign tumor excision, still external approach has some advantages over the endoscopic approach in advanced stage tumors. Tumor with lateral extension, gross involvement of skull base, tumor with cavernous sinus involvement with encasement of carotid artery, and the centers where embolization facility is not available, the external approach has a major advantage over the endoscopic approach. Various external surgical approaches have been proposed for this tumor excision.

\footnotetext{
${ }^{1}$ Assistant Professor, ${ }^{2-5}$ Senior Resident

1,3-5 Department of Otolaryngology and Head and Neck Surgery All India Institute of Medical Sciences, New Delhi, India

${ }^{2}$ Department of ENT and Head and Neck Surgery, All India Institute of Medical Sciences, New Delhi, India

Corresponding Author: Ashutosh Hota, Senior Resident Department of ENT and Head and Neck Surgery, All India Institute of Medical Sciences, New Delhi, India, Phone: +919818375955, e-mail: drashutoshhota@yahoo.com
}

Midfacial degloving, maxillary swing (facial translocation), and Le Fort approaches are the popular one. The main aim of this article is to introduce a novel approach of facial translocation without a palatal cut which is a major drawback of conventional maxillary swing where palatal fistula is a major complication.

\section{CASE REPORT}

An adolescent male came to our institute with history of nasal bleed since 8 months, with radiology suggestive of angiofibroma (Fig. 1). The tumor was extending from the left nasal cavity, pterygopalatine fossa, pterygomaxillary fissure to the infratemporal fossa. Preoperative embolization was done with gelfoam with significant decrease in tumor blush.

\section{OPERATIVE TECHNIQUE}

After inducing general anesthesia, temporary tarsorrhaphy was done. Weber-Ferguson incision was made on the left side. Lip split was not done. Incision was deepened up to the bone. Cheek flap was not elevated to preserve the blood supply to the maxilla. Zygoma, frontal process of the maxilla and the pyriform aperture were exposed. Osteotomies were made in the zygoma laterally below the orbit preserving the inferior orbital rim, in the frontal process of maxilla and, finally, in the pyriform aperture in the lateral nasal wall below the inferior turbinate

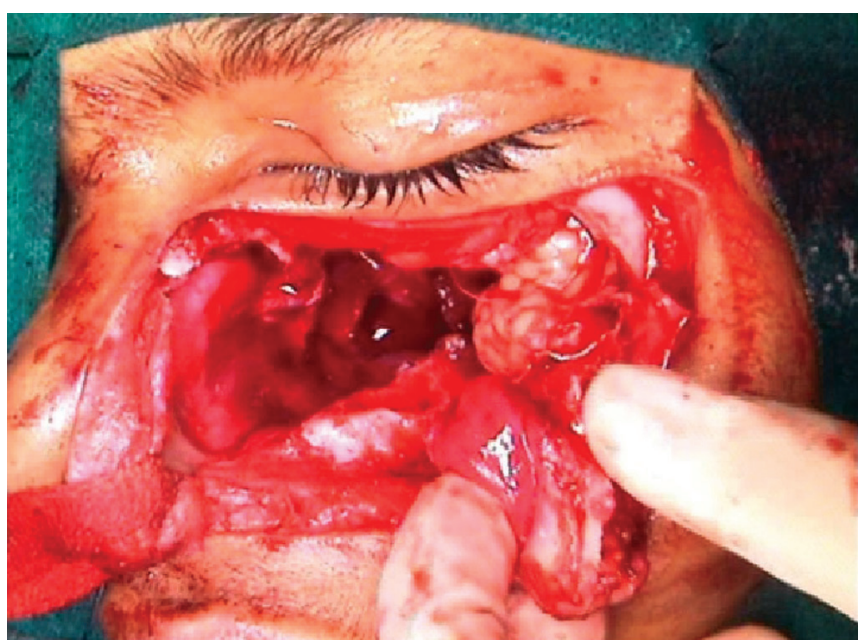

Fig. 1: Contrast enhanced computed tomography coronal cuts enhancing lesion within significant lateral extension to infratemporal fossa with sphenoid and base of pterygoid erosion 


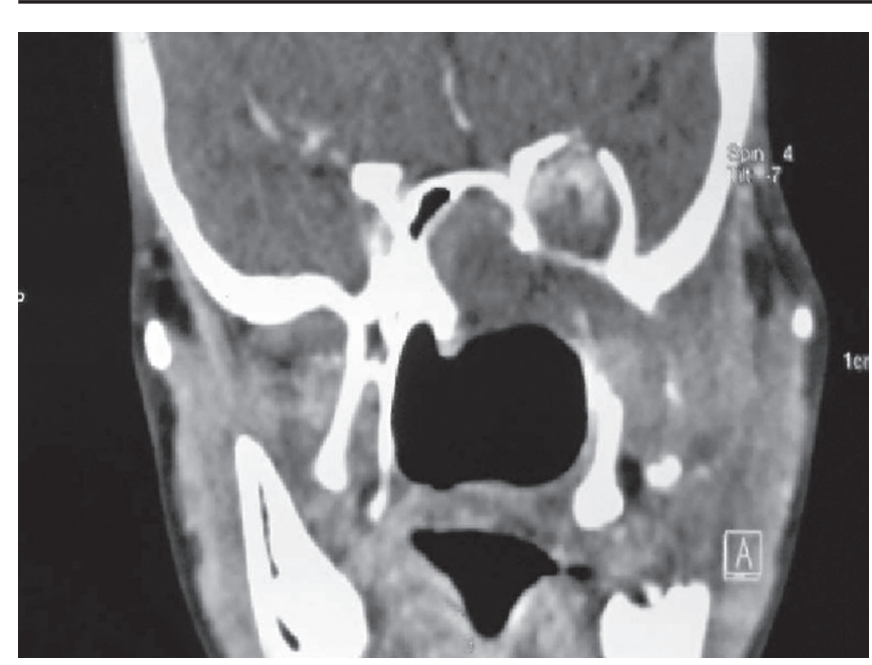

Fig. 2: Exposure with suprastructure maxillary swing

toward the nasopharynx. Palatal cuts and osteotomy in the midline in the anterior maxilla were not made. The maxilla was swung as an osteomyocutaneous unit based on cheek soft tissue (Fig. 2). Whole of the tumor was visualized and dissection was done in the subperiosteal plane from lateral to medial direction. Maxillary artery was ligated in the fatty tissue in the region of infratemporal fossa. Tumor attachment from the pterygoid base and pterygoid plates were removed with blunt meticulous dissection. Tumor was dissected from the lateral wall of nasopharynx and complete excision was performed. Base of pterygoid was drilled for microscopic clearance of disease to prevent the disease recurrence. Cheek flap along with the maxilla was put in position and the osteotomy sites were fixed.

\section{DISCUSSION}

Juvenile nasopharyngeal angiofibroma is a highly vascular skull base tumor exclusively affecting the young adolescent tumor. This tumor has a high recurrence rate. A wide exposure, dry surgical field is essential for complete disease clearance. Various surgical techniques with their advantages and disadvantages were described for angiofibroma excision (Table 1).

Maxillary swing is widely accepted as a surgical technique for exposure of central skull base, infratemporal fossa, pterygoid base, and nasopharynx. ${ }^{1}$ Midfacial degloving avoids the skin incision and is a more cosmetic approach, but it lacks more lateral and sphenoid exposure like the maxillary swing. Apart from skin incision, the major disadvantage of maxillary swing was risk of palatal fistula. ${ }^{2}$ Palatal fistula can be seen with vertical palatal incision to the palatal mucosa and the bone after angiofibroma excision. ${ }^{3}$ Palatal flap based on greater palatine artery should be made before
Table 1: Advantages and disadvantages of various approaches

\begin{tabular}{|c|c|c|}
\hline Types & $\begin{array}{l}\text { Surgical } \\
\text { approaches }\end{array}$ & Comments \\
\hline 1 & $\begin{array}{l}\text { Endoscopic } \\
\text { approach }\end{array}$ & $\begin{array}{l}\text { Excellent for tumor upto stage IIB } \\
\text { (modified Radkowski) }\end{array}$ \\
\hline 2 & $\begin{array}{l}\text { Transpalatal } \\
\text { approach }\end{array}$ & $\begin{array}{l}\text { No advantage to endoscopic } \\
\text { approach and risk of palatal fistula }\end{array}$ \\
\hline \multirow[t]{2}{*}{3} & \multirow{2}{*}{$\begin{array}{l}\text { Midfacial } \\
\text { degloving and } \\
\text { transmaxillary } \\
\text { approach }\end{array}$} & Avoid skin scar \\
\hline & & $\begin{array}{l}\text { Major complication - vestibular } \\
\text { stenois, hampers the growth of } \\
\text { maxilla leading to facial asymmetry }\end{array}$ \\
\hline 4 & Lateral rhinotomy & Lack lateral exposure \\
\hline \multirow[t]{2}{*}{5} & \multirow{2}{*}{$\begin{array}{l}\text { Maxillary swing } \\
\text { approach } \\
\text { (conventional) }\end{array}$} & Good lateral exposure \\
\hline & & $\begin{array}{l}\text { Disadvantage: Palatal fistula, facial } \\
\text { scar mark }\end{array}$ \\
\hline 6 & $\begin{array}{l}\text { Lateral skull base } \\
\text { approach }\end{array}$ & $\begin{array}{l}\text { Good infratemporal and cavernous } \\
\text { sinus exposure, risk of cranial nerve } \\
\text { palsies }\end{array}$ \\
\hline 7 & $\begin{array}{l}\text { Suprastructure } \\
\text { maxillary swing }\end{array}$ & $\begin{array}{l}\text { Advantage of maxillary swing } \\
\text { in terms of exposure with little } \\
\text { impact on the growth of maxilla } \\
\text { and avoiding the disadvantage of } \\
\text { maxillary swing (palatal fistula) }\end{array}$ \\
\hline
\end{tabular}

the bony cuts in palate to reduce the palatal fistula as described in the literature. ${ }^{4}$ Quality of life was severely affected in postoperative period with a palatal fistula. It affects the speech and swallowing of the patients. ${ }^{5}$ Treatment options are dental obturator and surgical repair of the fistula. Other transmaxillary approaches provide similar exposure but needs removal of lateral wall of nose and anterior and posterior wall of maxilla, which leads to facial deformity in this adolescent male. So with our method of suprastructure maxillary swing, palatal cuts and facial deformity can be avoided with minimal compromise in the exposure with avoidance of fistula formation for a benign tumor-like angiofibroma. We termed this technique as suprastructure maxillary swing because only the suprastructure of the maxilla has to be swung instead of the entire maxilla as in conventional maxillary swing.

\section{CONCLUSION}

Suprastructure maxillary swing is an excellent technique for exposure of nasopharynx, pterygomaxillary fossa, infratemporal fossa, central skull base, pterygoid base, and sphenoid, similar to the conventional maxillary swing, but lacks its major disadvantage of palatal fistula after JNA excision. Secondly, with this approach, the exposure is equivalent to the transmaxillary approach, but facial bone removal is hardly required, hence preventing the facial asymmetry in this young adolescent male. 


\section{REFERENCES}

1. Wei WI, Ho CM, Yuen PW, Fung CF, Sham JS, Lam KH. Maxillary approach for resection of tumors in and around the nasopharynx. Arch Otolaryngol Head Neck Surg 1995 Jun;121(6):638-642.

2. King WW, Ku PK, Mok CO, Teo PM. Nasopharyngectomy in the treatment of recurrent nasopharyngeal carcinoma: a twelve-year experience. Head Neck 2000 May;22(3):215-222.
3. Amin AA. Maxillary swing approach for surgical resection of recurrent nasopharyngeal tumors. J Egypt Natl Canc Inst 2007 Sep;19(3):219-223.

4. Ng RW, Wei WI. Elimination of palatal fistula after the maxillary swing procedure. Head Neck 2005 Jul;27(7):608-612.

5. Kornblith AB, Zlotolow IM, Gooen J, Huryn JM, Lerner T, Strong EW, Shah JP, Spiro RH, Holland JC. Quality of life of maxillectomy patients using an obturator prosthesis. Head Neck 1996 Jul-Aug;18(4):323-334. 